\title{
Non-odontogenic toothache revisited
}

\author{
Ramesh Balasubramaniam $^{1 *}$, Lena N. Turner ${ }^{2}$, Dena Fischer ${ }^{3}$, Gary D. Klasser ${ }^{4}$, Jeffrey P. Okeson ${ }^{5}$ \\ ${ }^{1}$ School of Dentistry, University of Western Australia, Perth, Australia; \\ ${ }^{2}$ Department of Oral Medicine, School of Dental Medicine, University of Pennsylvania, Philadelphia, America; \\ ${ }^{3}$ Department of Oral Medicine and Diagnostic Sciences, University of Illinois at Chicago, Chicago, America; \\ ${ }^{4}$ Division of Diagnostic Sciences, Louisiana State University Health Sciences Centre, School of Dentistry, New Orleans, America; \\ ${ }^{5}$ Department of Oral Health Science, University of Kentucky, Lexington, America. \\ Email: "ramesh.balasubramaniam@uwa.edu.au
}

Received 17 May 2011; revised 23 June 2011; accepted 5 July 2011.

\begin{abstract}
Although pain of dental origin is the most common orofacial pain, other non-odontogenic pains can affect the orofacial region and occasionally mimic dental pain. These non-odontogenic pains may pose a diagnostic dilemma for the dental practitioner who routinely diagnoses and treats dental pain. Knowledge of the various non-odontogenic pains will ultimately prevent misdiagnosis and the delivery of incorrect and sometimes irreversible and invasive procedures to patients. The purpose of this article is to review the clinical presentations of the various types of non-odontogenic pains which may be mistaken as dental pain: myofascial, cardiac, sinus, neurovascular, neuropathic, neoplastic and psychogenic pain.
\end{abstract}

Keywords: Non-Odontogenic Toothache; Orofacial Pain

\section{INTRODUCTION}

The orofacial region is the most frequent site for patients seeking medical attention for pain [1,2] with $12.2 \%$ of the population reporting dental pain as the most common orofacial pain [3]. Consequently, it is common for pain in the orofacial region to be mistaken for a toothache, and similarly, other pains of the head and neck to mimic odontogenic pain. Therefore, orofacial pain may pose a diagnostic dilemma for the dental practitioner. Understanding the complex mechanism of odontogenic pain and the manner in which other orofacial structures may simulate pain in the tooth is paramount in determining the correct diagnosis and appropriate treatment.

The purpose of this article is to: a) provide the dental practitioner with an understanding of pain etiology to consider when developing differential diagnoses for orofacial pains, and b) review various types of nonodontogenic pains which may be mistaken for a tooth- ache. Ultimately, this article will aid the dental practitioner with preventing misdiagnosis and delivery of incorrect and sometimes irreversible procedures for nonodontogenic pains.

\section{CLINICAL CHARACTERISTICS OF ODONTOGENIC PAIN}

Odontogenic pain is generally derived from either one of two structures associated with the tooth: pulpal or periodontal tissue. Although the mechanisms for both are of inflammatory origin, their distinct functionality and embryologic origin [4] results in each pain being perceived differently. Pulpitis is the most common cause of odontogenic pain [2] and can be divided into two categories: reversible and irreversible. Reversible pulpitis indicates that pulpal tissues can repair with the removal of the local irritant and restoration of the tooth structure. It is often characterized by a fleeting pain upon provocation and does not occur spontaneously. Irreversible pulpitis has a prolonged duration of pain when stimulated but may also occur spontaneously.

As a visceral organ, pain of the dental pulp is characterized by deep, dull, aching pain that may be difficult to localize [5]. It may present as intermittent or continuous, moderate or severe, sharp or dull, localized or diffuse and may be affected by the time of day or position of the body [6]. After prolonged periods of intense pain, referred pain may be produced due to central excitatory effects [7]. The quality of pain may vary based upon the vitality of the tooth as well as the extent of inflammation. Following prolonged periods of inflammation, pulpal necrosis may occur. Also, there may be other causes of pulpal pain that may be difficult to identify such as "cracked tooth syndrome" whereby a crack or craze may develop within the tooth [6].

Periodontal pain is more readily localized and identifiable because of proprioceptors located within the pe- 
riodontal ligament. Therefore, periodontal pain will follow the characteristics of pain of musculoskeletal origin. The periodontal receptors are able to accurately localize the pain whether they are lateral or apical to the tooth. Acute apical periodontitis may be the result of pulpal necrosis. Similarly, a lateral periodontal abscess may be a source of odontogenic pain and may be associated with clinical signs such as edema, erythema and swelling of the gingival [6]. The diagnosis of pulpal and periodontal pain is often easily established and once diagnosed, treatment is directed at alleviating the etiology. In rare cases, odontogenic pain can present as an enigma confusing the clinician. However, the clinician should be mindful that dental pain is the most common orofacial pain.

\section{CLINICAL CHARACTERISTICS OF NON-ODONTOGENIC PAIN}

The clinical presentation of non-odontogenic pain is varied and may mimic other pain disorders which may not originate in the orofacial region. The extent of pain may vary from very mild and intermittent pain to severe, sharp, and continuous. Furthermore, pains that are felt in the tooth do not always originate from dental structures, so it is important to distinguish between site and source of pain to provide correct diagnosis and appropriate treatments. The site of pain is where the pain is felt by the patient, whereas the source of pain is the structure from which the pain actually originates. In 'primary' pain, the site and source of pain are coincidental and in the same location. That is, pain occurs where damage to the structure has occurred. Therapy for primary pain is obvious and does not pose a diagnostic dilemma for the clinician.

Pain with different sites and sources of pain, known as heterotopic pains, can be diagnostically challenging. Once diagnosed, treatment should be posed at the source of pain, rather than the site. Neurologic mechanisms of heterotopic pain is not well understood but it is thought to be related to central effects of constant nociceptive input from deep structures such as muscles, joints and ligament [8].

Although the terms heterotopic pain and referred pain are often used interchangeably, there are specific distinctions between these terms. Heterotopic pain can be divided more specifically into 3 general types: a) central pain, b) projected pain, and c) referred pain [4]. Central pain is simply pain derived from the central nervous system (CNS) resulting in pain perceived peripherally. An example of central pain is an intracranial tumor as this will not usually cause pain in the CNS because of the brain's insensitivity to pain but rather it is felt peripherally. Projected pain is pain felt in the peripheral dis- tribution of the same nerve that mediated the primary nociceptive input. An example of projected pain is pain felt in the dermatomal distribution in post-herpetic neuralgia. Referred pain is spontaneous heterotopic pain felt at a site of pain with separate innervation to the primary source of pain. It is thought to be mediated by sensitization of interneurons located within the CNS. Pain referred from the sternocleidomastoid muscle to the temporomandibular joint is an example of referred pain [4]. The remainder of this article will focus on non-odontogenic pains of odontogenic origin.

\subsection{Myofascial Toothache}

Skeletal muscle triggers are well recognized in the literature $[9,10]$ and are illustrated by trigger point mapping achieved through palpation of the muscles and describing the locations of pain referral $[11,12]$. The trigger point, a localized hyperexcitable nodule within the muscle, is theorized to be a result of microscopic neuromuscular dysfunction at the motor endplate [12]. As it cannot be identified histologically or by imaging, there is controversy as to the true existence of the trigger point $[12,13]$. Clinically, palpating a firm, tender nodule within a sufficiently irritable muscle may reproduce referred pain to distant regions upon sustained pressure [12,14]. Hong et al. were able to reproduce referred pain $80 \%$ of the time by palpation of the trigger point with sufficient pressure for up to 10 seconds [15]. An additional study was able to reproduce muscle pain with dry needling of the muscle in $62 \%$ of the cases [15].

The theory of convergence supports the mechanism that is thought to cause pain referral to the trigeminal sensory complex from other areas of nociceptive input although it is not well understood. It has been reported that at least half of the trigeminal nociceptive neurons are able to be activated by stimulation outside their normal receptive field [16]. Studies on myofascial pain referral to other regions of the orofacial region have found that pain from: a) temporalis muscles referred pain to the maxillary teeth, b) masseter muscles referred pain to the maxillary and mandibular posterior teeth, ear and temporomandibular joint (TMJ), c) lateral pterygoid muscles referred pain to the maxillary sinus region and TMJ, d) anterior digastric muscles referred pain to the mandibular incisors, and e) sternocleidomastoid muscles referred pain to oral structures and the forehead $[11,12,17]$. Additionally, palpation of the trapezius muscle often refers pain to the mandible or temporalis muscle regions [4,12].

The myofascial toothache is described as non-pulsatile and aching pain and occurs more continuously than pulpal pain [6]. Patients are unable to accurately locate the source of the pain and often believe pain is originating 
from the tooth. Tooth sensitivity to temperature, percussion or occlusal pressure may be felt as a result of referred pain from the offending muscle [12]. Pain tends to be associated with extended muscle use and exacerbated with emotional stressors, rather than direct provocation of the affected tooth [6]. Palpation of the trigger point is able to reproduce the toothache, even modulate the pain by increasing or eliminating it altogether [6]. In spite of this, it has been reported that $7 \%$ of cases were referred for endodontic treatment when the primary source of pain was the muscle of mastication [18]. Linn et al. reported that $37 \%$ of patients diagnosed with muscular orofacial pain had previously undergone endodontic or exodontic treatment in an attempt to alleviate their pain [19].

Alleviation of the toothache is often achieved when local anesthetic is administered to the strained muscle (source of pain) rather than the tooth (site of pain). Warm or cold compresses, muscle stretching, massage, and a restful sleep may alleviate both the muscle and tooth pain. Elimination of the trigger point and pain of the muscle should be the aim of the treatment rather than the tooth itself $[1,6]$.

\subsection{Cardiac Toothache}

Cardiac pain is an additional source of referred pain to the jaw mainly due to cardiac ischemia. Angina pectoris is a symptomatic presentation of ischemic heart disease that is often used in congruence with cardiac ischemia. Cardiac ischemia more commonly presents with substernal pain and radiation to the left shoulder and arm [6]. When cardiac pain presents in the orofacial region commonly affected areas include pain(s) in the neck, throat, ear, teeth, mandible and headache [20-24]. In some cases, orofacial pain is the only complaint in association with cardiac ischemia. In one study, 6\% of patients presenting with coronary symptoms had pain solely in the orofacial region while $32 \%$ had pain referred elsewhere. Interestingly, bilateral referred craniofacial pain was noted more commonly than unilateral pain at a ratio of 6:1 [20].

The mechanism of cardiac pain likely involves multiple nociceptive mediators with bradykinin being the most important, evoking a sympathoexcitatory reflex [25] and inducing a sympathetic response of the heart [26-28]. Although widely accepted, there is controversy as to whether the sympathetic response is responsible for the transmission of pain. Studies on patients who underwent sympathectomies demonstrated a 50\% - 60\% complete relief of angina pectoris, while $40 \%$ obtained a partial relief, and $10 \%$ - 20\% experienced no relief [29].

Vagal afferent response is thought to also play a role in the response to cardiac ischemia although its role is not clearly defined [30,31]. Based on the anatomic distribution, vagal afferents could be activated when the infero-posterior surface of the heart is affected, while sympathetic response is due to stimulation of the anterior portion [29]. A recent case report suggests an association between vagal stimulation and toothache in a patient undergoing experimental treatment with a vagal nerve stimulator for the treatment of depression [32]. Episodes of tooth pain were coincidental to duration and frequency of nerve stimulation and once appropriate adjustments to the stimulator parameters were made, the dental pain subsided. Vagal stimulation has been utilized in other treatments such as drug resistant epilepsy, and reports of similar painful side effects such as jaw and tooth pain as well as throat and neck pain have been noted [33-36]. Consequently, there may be a physiologic association between vagal stimulation initiated by cardiac ischemia and odontogenic pain.

Mechanisms of convergence and central sensitization in the trigeminal nerve complex can also explain pain referred to orofacial structures [4]. Cardiac nociceptive input travels to the central nervous system and ascends to higher centers for processing in regions of convergence, where adjacent nociceptive neurons may become activated [37]. The stimulation of adjacent neurons that are not directly involved in the primary source of pain may be misinterpreted in the cortex, causing an unintentional pain input being referred to other regions and resulting in heterotopic pain.

Alternate sources of pain should be considered when local anesthetic and analgesics fail to alleviate dental symptoms. Appropriate questioning and thorough medical history are essential in identifying the true source of pain, especially when a cardiac toothache is suspected. Clinical characteristics of pain may vary between patients. Pain may be episodic, lasting from minutes to hours, and varies in intensity, although almost invariably is precipitated by exertional activities and alleviated with rest [37]. Intriguingly, patients experiencing cardiac pain reported the descriptor of "pressure" more often when compared to any other disorder [38].

If the pain is associated with cardiac or chest pain, it is most often relieved by sublingual nitroglycerin and immediate referral to a medical practitioner is imperative.

\subsection{Sinus Toothache}

Sinusitis is a common aliment in the US, resulting in about 16 million visits to the physician annually [39,40]. Approximately, $15 \%$ of the population reports it as a chronic problem, [41] with about $10 \%$ of maxillary sinusitis cases being diagnosed as having an odontogenic origin [42]. Since the roots of the maxillary dentition are in intimate contact with, and often protruding into, the sinus cavity, it is comprehensible that the dentition could be a potential source of sinus inflammation and infection. 
As the maxillary sinus grows, its final point of growth is coincidental with the growth of the maxillary alveolar process and eruption of the permanent dentition. This may result in a protrusion of roots into the sinus cavity that, in some cases, may be separated only by the Schneiderian membrane (mucoperiosteum) [43].

Due to the close proximity between maxillary posterior roots and the maxillary sinus, an infectious process in the dentition or surrounding periodontal tissue may present as an acute or chronic sinusitis; conversely, inflammation and infection originating in the maxillary sinus may be perceived as odontogenic pain. Patients may present with facial pain and pressure in the maxillary posterior region. Other symptoms such as headache, halitosis, fatigue, cough, nasal discharge/drainage or congestion and ear pain may be more identifiable as being associated with sinus disease [44]. Sinus pain can also present as a continuous dull ache or diffuse lingering pain in the maxillary teeth $[8,45]$ with sensitivity to percussion, mastication, and/or temperature. This hypersensitivity is often felt in multiple teeth, making it more indicative of a pain of sinus origin rather than odontogenic pain $[8,46]$.

Often a history of respiratory infection, nasal congestion, and sinus disease may precede the onset of the toothache [8]. Pain may be elicited by palpation of the infraorbital regions or maneuvering the head to below the levels of the knees, initiating gravitational shifting of fluid in the sinus $[8,47]$. The absence of an offending tooth or gingival inflammation upon intraoral examination may further lead to the conclusion that there is sinus inflammation or infection. Although chronic sinusitis may erode the wall of the sinus, it is rarely associated with intraoral soft tissue swelling or pain [48]. Intraoral or panoramic radiographs may be useful to exclude the dentition as being the source of the problem. The sinuses may appear cloudy, opacified, and congested on the panoramic radiograph. Increased fluid levels and thickening of the sinus mucosal membrane may be apparent on CT scan [8].

Once identified, treatment should be directed toward the maxillary sinus infection. Most cases of acute sinusitis are of viral origin and require nasal decongesttants, a therapy targeted at reducing the soft tissue edema to allow drainage of the sinus through the ostium into the middle meatus of the nasal cavity [46]. In the cases of bacteria-induced sinusitis, a regimen of antibiotics is additionally prescribed [46]. Management is beyond the scope of a dental professional and appropriate referral to an otorhinolaryngologist or the general medical practitioner is appropriate once there is a clear understanding that the source of the odontogenic pain is of sinus origin.

\subsection{Neurovascular Toothache}

Neurovascular pains or headache is a common complaint. Typically "headache" is pain localized to the cranium. However, headache may also present as a variant involving the orofacial region hence mimicking toothache. Two primary headache types that may present as toothache are migraine and trigeminal autonomic cephalalgia (Table 1).

The 1-year period prevalence for migraine is $11.7 \%$ (17.1\% in women and 5.6\% in men) [49]. Migraines are typically unilateral, moderate to severe pains of pulsatile and throbbing quality that are often disabling. Pain usually lasts between 4 and 72 hours and may be aggravated by routine physical activities. Migraine is often accompanied by nausea, vomiting, phonophobia and/or photophobia and may present with (20\%) or without aura (80\%). An aura is a reversible focal neurological symptom (visual, sensory and motor phenomena) that develops between 5 and 20 minutes, subsides within 60 minutes and is immediately followed by a headache [50].

Although its prevalence is unknown, Migraine may present in the midface without involvement of the first division of the trigeminal nerve [51]. Also there are a few case reports of patients with oral and dental pain subsequently diagnosed as migraine [52,53]. Obermann et al. [54] in a case series involving 7 patients reported migraine presenting in the face occurred more often in the maxillary division than the mandibular division of the trigeminal nerve. Apart from location, the migraine limited to the orofacial region is similar to "cranial" migraine. Penarrocha et al. [55] reviewed 11 patients with "lower-half facial migraine" and reported that $45 \%$ had endodontic treatment prior to initially developing pain. Four of these patients reported a history of migraine prior to the development of "lower-half facial migraine". Of concern, the average time elapsed prior to proper diagnosis was 101 months (6 to 528 months). Also, 36\% of cases had teeth extracted in an attempt to treat the pain. Benoliel et al. [56] diagnosed 23 of 328 patients with "neurovascular orofacial pain" over a 2-year period and proposed an expansion of the current International Headache Society classification to include orofacial pain syndromes.

Trigeminal autonomic cephalalgias (TACs) are a collective term that refers to a group of headaches characterized by unilateral head and/or face pain with accompanying autonomic features [50,57]. The International Classification of Headache Disorders II (ICHD-II) classifies TACs as: 1) episodic or chronic cluster headache $(\mathrm{CH})$; 2) episodic or chronic paroxysmal hemicrania (PH) and 3) Short-lasting Unilateral Neuralgiform headache attacks with Conjunctival injection and Tearing (SUNCT) 
[50].

Although rare, TACs may present a challenge for the dentist due to its often overlapping and similar presentations to true odontogenic pains (Table 1). Individuals often describe the location of pain due to $\mathrm{CH}$ emanating from the midface region which may be interpreted as pain originating from the teeth, jaws or the temporomandibular joints [58,59]. Bahra and Goadsby [60] reported that $45 \%$ of a group of $\mathrm{CH}$ patients were seen by a dentist prior to receiving the correct diagnosis. They also found that a misdiagnosis provided by a dentist often led to unnecessary and inappropriate dental procedure(s). In another study, it was found that $42 \%$ of 33 $\mathrm{CH}$ patients received some form of invasive and irreversible dental procedure as their treatment [61]. It has been postulated that dental extractions may be a precipitating factor for $\mathrm{CH}$. Penarrocha et al., [62] in a study of $54 \mathrm{CH}$ patients, found that prior tooth extraction or endodontics had been performed in the pain affected quadrant in 31 (58\%) of the subjects and in the contralateral quadrant in 18 (33\%) subjects. Additionally, they found that in 24 (44\%) cases, tooth extraction was performed after the onset of pain in an attempt to solve the problem with only 1 patient reporting improvement.

Due to the short duration of attacks, recurrences, excruciating intensity and pulsatile pain quality found in $\mathrm{PH}$, it is possible that this disorder may be mistaken for dental pulpitis [63]. It is also not uncommon for PH to manifest in the maxillary region thereby being mistaken for tooth pain [64]. Benoleil and Sharav [65] reported on $7 \mathrm{PH}$ cases, 4 of which had been confused for pain of dental origin. Two of these patients received irreversible dental treatments. Other studies have reported similar occurrences whereby the spectrum of failed dental treatment ranged from pharmacological approaches to full mouth reconstruction [52,66-68].

Although rare, there are case reports in which SUNCT patients, in addition to facial pain, complain of pain radiating to adjacent teeth. This has resulted in dentists delivering therapeutic interventions for tooth pain such as extraction, occlusal splints and incorrect pharmacology [69-71]. In order for dentists to avoid the pitfalls of providing unnecessary interventions for misdiagnosed toothaches of neurovascular origin, they must perform a thorough history and comprehensive clinical examination. If this process does not yield convincing evidence of pain from an odontogenic origin then referral to the appropriate practitioner should be pursued.

\subsection{Neuropathic Toothache}

Neuropathic pain refers to a pain that originates from abnormalities in the neural structures and not from the tissues that are innervated by those neural structures. These pains pose significant difficulty for the clinician since the structures the patient reports as painful appear clinically normal. There are two types of neuropathic pains that can be felt in teeth: episodic and continuous.

Table 1. Differentiating features of neurovascular pain and dental pain [111,112].

\begin{tabular}{|c|c|c|c|c|c|c|c|}
\hline Feature & Migraine & $\begin{array}{c}\text { Cluster } \\
\text { headache }\end{array}$ & $\begin{array}{l}\text { Paroxysmal } \\
\text { hemicrania }\end{array}$ & SUNCT & $\begin{array}{c}\text { Acute } \\
\text { pulpal pain }\end{array}$ & $\begin{array}{c}\text { Chronic } \\
\text { pulpal pain }\end{array}$ & $\begin{array}{l}\text { Periodontal } \\
\text { pain }\end{array}$ \\
\hline Sex (male:female) & $1: 3$ & $5: 1$ & $1: 2$ & $2: 1$ & $1: 1$ & $1: 1$ & $1: 1$ \\
\hline Age (years) & $10-50$ & $20-40$ & 30 & $40-70$ & any age & any age & any age \\
\hline Pain type & pulsating & boring & boring & electric-like & $\begin{array}{l}\text { throbbing or } \\
\text { aching }\end{array}$ & tender or aching & $\begin{array}{l}\text { tender or } \\
\text { aching }\end{array}$ \\
\hline Pain severity & moderate to severe & very severe & very severe & very severe & mild to severe & mild & mild \\
\hline Pain location & frontotemporal & orbital & orbital & orbital & tooth & tooth & $\begin{array}{l}\text { tooth/gingival } \\
\text { /bone }\end{array}$ \\
\hline Pain duration & 4 - 72 hours & $\begin{array}{l}15-180 \\
\text { minutes }\end{array}$ & $\begin{array}{c}2 \text { - } 30 \\
\text { minutes }\end{array}$ & $\begin{array}{l}15 \text { - } 240 \\
\text { seconds }\end{array}$ & $\begin{array}{c}\text { seconds to } \\
\text { daily }\end{array}$ & constant & variable \\
\hline Pain frequency & 1/month & 1 - 8/day & 2 - 40/day & 3 - 200/day & variable & Daily & Daily \\
\hline $\begin{array}{l}\text { Autonomic } \\
\text { features }\end{array}$ & No; may have with aura & Yes & Yes & Yes & No & No & No \\
\hline Trigger & $\begin{array}{l}\text { stress, foods, vasodilators, } \\
\text { sleep pattern changes, } \\
\text { afferent stimulation, } \\
\text { hormonal changes }\end{array}$ & $\begin{array}{c}\text { alcohol, } \\
\text { nitrates }\end{array}$ & mechanical & cutaneous & $\begin{array}{l}\text { electric \& thermal } \\
\text { stimulation, } \\
\text { tooth percussion }\end{array}$ & inconsistent & $\begin{array}{l}\text { apical or lateral } \\
\text { tooth pressure }\end{array}$ \\
\hline
\end{tabular}


Episodic neuropathic pain is characterized by sudden volleys of electric-like pain referred to as neuralgia. The most typical example of this type of pain is trigeminal neuralgia. When this type of paroxysmal pain is felt in a tooth it can pose significant diagnostic challenges for the clinician. The clinical presentation of an episodic neuropathic toothache is a severe, shooting, electric-like pain that lasts only a few seconds $[4,72,73]$. The pain is not always restricted to a tooth but often a broader area. The pain is not altered by intraoral thermal stimuli $[4,6,72]$. It rarely awakes the patient from sleep unlike dental pain. The most common branch of the trigeminal nerve involved is the mandibular followed by the maxillary and least involved is the ophthalmic [4,72]. The pain is often severe with patients reporting the pain as being the most intense they have ever experienced. Often the patient is able to trace the pain radiating down the distribution of the nerve to the tooth [6].

With trigeminal neuralgia there is often a trigger zone that, when lightly stimulated, provokes the severe paroxysmal pain. Anesthetic blocking of the trigger zone will completely eliminate the toothache and paroxysmal episodes during the period of anesthesia. On occasion a tooth can represent the trigger zone, and if this occurs, it can pose a great diagnostic challenge for the clinician. Patients with trigeminal neuralgia frequently receive endodontic treatment for their dental pain [74,75]. Additional case reports also provide examples of the opposite diagnostic problem: patients with odontogenic dental pain being diagnosed as having trigeminal neuralgia [76]. In both types of misdiagnosis, the lack of response to treatment is a key factor in prompting reassessment of the differential diagnosis.

Continuous neuropathic pains are pain disorders that have their origin in neural structures and are expressed as constant, ongoing and unremitting pain. They will often have high and low intensity but no periods of total remission. Continuous neuropathic pains that can be felt in teeth have been referred to as atypical odontalgia $[77,78]$ or sometimes phantom toothache $[79,80]$. Continuous neuropathic pain appears to have its origin associated with central plasticity in the trigeminal nuclear complex of the brain stem [81]. In some instances there may be a sympathetic component to the pain [82]. Patients with continuous neuropathic toothache often report a history of trauma or ineffective dental treatment in the area [83]. In a study of 42 patients with atypical odontalgia, $86 \%$ of the patient population was female and $78 \%$ reported maxillary pain. Of 119 reported areas of pain, the most common were the molar (59\%), premolar (27\%), and canine $(4 \%)$ regions $[84,85]$. The pain may change in location over time; some studies have reported pain shifting location in up to $82 \%$ of the subjects
$[82,86]$.

It is not unusual for patients with continuous neuropathic toothache to have received multiple endodontic treatments or extractions for their dental pain [84,86-90]. In many cases, the lack of response to treatment is a key factor in prompting reassessment of the differential diagnosis [91]. Ram et al. [92] in their retrospective study involving 64 patients reported that $71 \%$ had initially consulted a dentist for their pain complaint, and subsequently $79 \%$ of patients received dental treatment that did not resolve the pain. In one case report, the lack of an effect of a local anesthetic injection on reducing the intensity of pain was a significant finding that prompted consideration of non-odontogenic tooth pain [90].

The following characteristics of continuous neuropathic toothache can be used to differentiate it from odontogenic pain: a) diffuse pain, b) pain not always restricted to a tooth (e.g., the area may be edentulous), c) pain that is almost always continuous, d) a pain quality often described as a dull, aching, throbbing, or burning, e) pain that may or may not be relieved by a diagnostic intraoral local anesthetic block, f) pain that often lasts more than 4 months, and g) pain not altered by intraoral thermal stimuli $[4,6,82,85,88,93,94]$.

\subsection{Neoplastic Toothache}

Orofacial pain may be the initial symptom of oral cancer and can motivate patients to seek care from their dental practitioners. Primary squamous cell carcinoma (SCC) of the oral mucosa may present with pain and sensory disturbances that mimic toothache symptoms particularly when located on the gingiva, vestibule or floor of mouth. One retrospective case series found pain to be the first clinical sign of oral cancer in $19.2 \%$ of cases [95], while other literature has suggested that two-thirds of patients with oral cancer have reported localized discomfort within the 6 months preceding a cancer diagnosis [96]. Primary intraosseous carcinoma is a SCC that occurs within the jaws, has no initial connection with the oral mucosa, and arises from either a previous odontogenic cyst or de novo [97]. These malignancies are extremely rare, but when they do occur, they can be mistaken for odontogenic origin since the clinical presentation of localized bone loss may have the appearance of localized periodontal disease.

Nasopharyngeal cancers may present with signs and symptoms that have been confused with, and treated as, temporomandibular disorders [98,99], parotid gland lesions [100], and odontogenic infections with trismus [101]. While signs and symptoms of nasopharyngeal carcinomas may mimic temporomandibular disorders, such as facial pain, limited jaw opening, deviation of the 
jaw on opening, earache, and headache [98,99], some of these signs may also be found and confused with an odontogenic etiology.

Systemic cancers such as lymphoma and leukemia may have intraoral manifestations that mimic toothachelike symptoms. Such cancers can infiltrate pain-sensitive structures such as periosteum and gingiva, thereby causing localized pain that may be confused with odontogenic and/or periodontal conditions [102]. In rare circumstances, the osseous osteolytic lesions of multiple myeloma may develop adjacent to teeth. When this occurs, odontogenic pain is common and presents a radiologic diagnostic challenge as the osteolytic lesions appear to be associated with teeth but are actually related to the systemic disease [103].

Orofacial pain has also been reported in patients with distant non-metastasized cancers, most commonly from the lungs [104-107]. In such circumstances, the facial pain is almost always unilateral affecting the ear, jaws and temporal region, frequently described as severe and aching, and usually continuous and progressive. Such a presentation may be confused with referred pain of odontogenic origin.

Orofacial pain may be associated with metastatic malignancies and when metastatic orofacial tumors occur, they affect the jaw bones more often than the oral soft tissues [108]. Metastases most often develop from the breast in women and the lung and prostate in males, with the most common sites of occurrence in the jaws being the posterior mandible, angle of the jaw, and ramus [108, 109]. Pain is a rare complaint in soft tissue metastases [110], whereas in metastatic disease of the jaw bones, pain has been reported in 39\% and paresthesias in 23\% of patients [111]. The pain and clinical presentation can be misinterpreted as that originating from an odontogenic source. In a retrospective case series of metastatic disease in the jaws, 60\% of 114 cases reported the metastatic lesion in the oral region to be the first indication of an undiscovered primary malignancy at a distant site [109].

Signs and symptoms of orofacial malignancies may mimic odontogenic etiology. It is important for dental practitioners to use appropriate judgment when clinical findings do not correlate with the results of odontogenic diagnostic testing. Neoplastic toothache must be considered when localized soft or hard tissue changes develop in close proximity to odontogenic structures and diagnostic findings are equivocal or negative.

\subsection{Psychogenic Toothache}

Psychogenic pain is pain that is associated with psychologic factors in the absence of any physiologic cause. The American Psychiatric Association has classified this condition as a somatoform pain disorder [112], indicating that clear evidence of a causal relationship between pain and psychologic factors is not required. While psychologic factors may be implicated, pain conditions classified under this definition may occur without the role of psychologic factors [113].

Pain descriptors are often diffuse, vague, and difficult to localize [113]. When the somatoform pain disorder is felt in the teeth, multiple teeth are often involved [6]. Pain may be sharp, stabbing, intense, and sensitive to temperature changes, all of which are similar to pain symptoms of odontogenic origin. However, the pain is inconsistent with normal patterns of physiologic pain and presents without any identifiable pathologic cause. When accompanied by other psychiatric features such as hallucinations or delusions, there is a greater possibility that the pain is of psychogenic origin [113].

Given that psychogenic toothache is a somatoform disorder, dental treatment will not resolve symptoms of pain and may potentially elicit an unexpected or unusual response to therapy [6]. Patients should be referred to a psychiatrist or psychologist for further management.

\section{CONCLUSIONS}

There are a multitude of non-odontogenic pains that can present at the site of a tooth and can mimic a toothache. Dental practitioners should also have an understanding of the complex mechanism of odontogenic pain and the manner in which other orofacial structures may simulate dental pain. In patients who present with toothache pain, dental practitioners should consider alternate etiologies of the pain when appropriate diagnostic tests do not lead to odontogenic etiology. Failure to establish the etiology of the pain will result in incorrect diagnosis and inappropriate treatment.

\section{REFERENCES}

[1] Sarlani, E., Balciunas, B.A., and Grace, E.G. (2005) Orofacial pain-Part II: Assessment and management of vascular, neurovascular, idiopathic, secondary, and psychogenic causes. AACN Clinical Issues, 16, 347-358. doi:10.1097/00044067-200507000-00008

[2] Annino, D.J. and Goguen, L.A. (2003) Pain from the oral cavity. Otolaryngologic Clinics of North America, 36, 1127-1135. doi:10.1016/S0030-6665(03)00132-4

[3] Lipton, J.A., Ship, J.A. and Larach-Robinson, D. (1993) Estimated prevalence and distribution of reported orofacial pain in the United States. The Journal of the American Dental Association, 124, 115-121.

[4] Okeson, J.P. (2005) Bell's orofacial pains: The clinical management of orofacial pain. Quintessence, Chicago.

[5] Ikeda, H. and Suda, H. (2003) Sensory experiences in relation to pulpal nerve activation of human teeth in different age groups. Archives of Oral Biology, 48, 835-841. 
doi:10.1016/S0003-9969(03)00176-6

[6] Okeson, J.P. and Falace, D.A. (1997) Nonodontogenic toothache. Dental Clinics of North America, 41, 367-383.

[7] Falace, D.A., Reid, K. and Rayens, M.K. (1996) The influence of deep (odontogenic) pain intensity, quality, and duration on the incidence and characteristics of referred orofacial pain. Journal of Orofacial Pain, 10, 232-239.

[8] Okeson, J.P. (2000) Non-odontogenic toothache. Northwest Dent, 79, 37-44.

[9] Davidoff, R.A. (1998) Trigger points and myofascial pain: Toward understanding how they affect headaches. Cephalalgia, 18, 436-448. doi:10.1046/j.1468-2982.1998.1807436.x

[10] Mense, S. (2003) The pathogenesis of muscle pain. Current Pain and Headache Reports, 7, 419-425. doi:10.1007/s11916-003-0057-6

[11] Fricton, J.R., Kroening, R., Haley, D. and Siegert, R. (1985) Myofascial pain syndrome of the head and neck: A review of clinical characteristics of 164 patients. Oral Surgery, Oral Medicine, Oral Pathology, 60, 615-623. doi:10.1016/0030-4220(85)90364-0

[12] Simons, D.G., Travell, J.G. and Simons, L.S. (1999) Travell and Simons' myofascial pain and dysfunction: The trigger point manual. 2nd Edition, Williams \& Wilkins.

[13] Jerjes, W., Hopper, C., Kumar, M., Upile, T., Madland, G., Newman, S., et al. (2007) Psychological intervention in acute dental pain: Review. British Dental Journal, 202, 337-343. doi:10.1038/bdj.2007.227

[14] Fricton, J.R. (1995) Management of masticatory myofascial pain. Seminars in Orthodontics, 1, 229-243. doi:10.1016/S1073-8746(95)80054-9

[15] Hong, C.Z., Kuan, T.S., Chen, J.T. and Chen, S.M. (1997) Referred pain elicited by palpation and by needling of myofascial trigger points: A comparison. Archives of Physical Medicine and Rehabilitation, 78, 957-960. doi:10.1016/S0003-9993(97)90057-5

[16] Sessle, B.J., Hu, J.W., Amano, N. and Zhong, G. (1986) Convergence of cutaneous, tooth pulp, visceral, neck and muscle afferents onto nociceptive and non-nociceptive neurones in trigeminal subnucleus caudalis (medullary dorsal horn) and its implications for referred pain. Pain, 27, 219-235. doi:10.1016/0304-3959(86)90213-7

[17] Wright, E.F. (2000) Referred craniofacial pain patterns in patients with temporomandibular disorder. The Journal of the American Dental Association, 131, 1307-1315.

[18] Ehrmann, E.H. (2002) The diagnosis of referred orofacial dental pain. Australian Endodontic Journal, 28, 75-81. doi:10.1111/j.1747-4477.2002.tb00388.x

[19] Linn, J., Trantor, I., Teo, N., Thanigaivel, R. and Goss, A.N. (2007) The differential diagnosis of toothache from other orofacial pains in clinical practice. Australian Dental Journal, 52, 100-104. doi:10.1111/j.1834-7819.2007.tb00518.x

[20] Kreiner, M., Okeson, J.P., Michelis, V., Lujambio, M. and Isberg, A. (2007) Craniofacial pain as the sole symptom of cardiac ischemia: A prospective multicenter study. The Journal of the American Dental Association, 138, 74-79.

[21] Tzukert, A., Hasin, Y. and Sharav, Y. (1981) Orofacial pain of cardiac origin. Oral Surgery, Oral Medicine, Oral Pathology, 51, 484-486.

\section{doi:10.1016/0030-4220(81)90006-2}

[22] Batchelder, B.J., Krutchkoff, D.J. and Amara, J. (1987) Mandibular pain as the initial and sole clinical manifestation of coronary insufficiency: Report of case. The Journal of the American Dental Association, 115, 710-712.

[23] Takayanagi, K., Fujito, T., Morooka, S., Takabatake, Y. and Nakamura, Y. (1990) Headache angina with fatal outcome. Japanese Heart Journal, 31, 503-507. doi:10.1536/ihj.31.503

[24] Ishida, A., Sunagawa, O., Touma, T., Shinzato, Y., Kawazoe, N. and Fukiyama, K. (1996) Headache as a manifestation of myocardial infarction. Japanese Heart Journal, 37, 261-263. doi:10.1536/ihj.37.261

[25] Veelken, R., Glabasnia, A., Stetter, A., Hilgers, K.F., Mann, J.F. and Schmieder, R.E. (1996) Epicardial bradykinin B2 receptors elicit a sympathoexcitatory reflex in rats. Hypertension, 28, 615-621.

[26] White, J.C. (1957) Cardiac pain: Anatomic pathways and physiologic mechanisms. Circulation, 16, 644-655.

[27] Staszewska-Barczak, J. and Dusting, G.J. (1977) Sympathetic cardiovascular reflex initiated by bradykinin-induced stimulation of cardiac pain receptors in the dog. Clinical and Experimental Pharmacology and Physiology, 4, 443-452. doi:10.1111/j.1440-1681.1977.tb02408.x

[28] Pal, P., Koley, J., Bhattacharyya, S., Gupta, J.S. and Koley, B. (1989) Cardiac nociceptors and ischemia: Role of sympathetic afferents in cat. The Japanese Journal of Physiology, 39, 131-144. doi:10.2170/jjphysiol.39.131

[29] Meller, S.T. and Gebhart, G.F. (1992) A critical review of the afferent pathways and the potential chemical mediators involved in cardiac pain. Neuroscience, 48, 501-524. doi:10.1016/0306-4522(92)90398-L

[30] Meller, S.T., Lewis, S.J., Ness, T.J., Brody, M.J. and Gebhart, G.F. (1990) Vagal afferent-mediated inhibition of a nociceptive reflex by intravenous serotonin in the rat. I. characterization. Brain Research, 524, 90-100.

[31] James, T.N. (1989) A cardiogenic hypertensive chemoreflex. Anesth Analg, 69, 633-646. doi:10.1213/00000539-198911000-00016

[32] Myers, D.E. (2008) Vagus nerve pain referred to the craniofacial region. A case report and literature review with implications for referred cardiac pain. British Dental Journal, 204, 187-189. doi:10.1038/bdj.2008.101

[33] Liporace, J., Hucko, D., Morrow, R., Barolat, G., Nei, M., Schnur, J., et al. (2001) Vagal nerve stimulation: Adjustments to reduce painful side effects. Neurology, 57, 885886.

[34] Rush, A.J., Marangell, L.B., Sackeim, H.A., George, M.S., Brannan, S.K., Davis, S.M., et al. (2005) Vagus nerve stimulation for treatment-resistant depression: A randomized, controlled acute phase trial. Biological Psychiatry, 58, 347-354. doi:10.1016/j.biopsych.2005.05.025

[35] Carius, A. and Schulze-Bonhage, A. (2005) Trigeminal pain under vagus nerve stimulation. Pain, 118, 271-273. doi:10.1016/j.pain.2005.07.022

[36] Shih, J.J., Devier, D. and Behr, A. (2003) Late onset laryngeal and facial pain in previously asymptomatic vagus nerve stimulation patients. Neurology, 60, 1214.

[37] Kreiner, M. and Okeson, J.P. (1999) Toothache of cardiac origin. Journal of Orofacial Pain, 13, 201-207. 
[38] Kreiner, M., Falace, D., Michelis, V., Okeson, J.P. and Isberg, A. (2010) Quality difference in craniofacial pain of cardiac vs. dental origin. Journal of Dental Research, 89, 965-969. doi:10.1177/0022034510370820

[39] Fagnan, L.J. (1998) Acute sinusitis: A cost-effective approach to diagnosis and treatment. American Family Physician, 58, 1795-1802, 1805-1806.

[40] (2000) Antimicrobial treatment guidelines for acute bacterial rhinosinusitis. Sinus and Allergy Health Partnership. Otolaryngology—Head and Neck Surgery, 123, 5-31.

[41] Piccirillo, J.F., Mager, D.E., Frisse, M.E., Brophy, R.H. and Goggin, A. (2001) Impact of first-line vs second-line antibiotics for the treatment of acute uncomplicated sinusitis. The Journal of the American Medical Association, 286, 1849-1856. doi:10.1001/jama.286.15.1849

[42] Mehra, P. and Murad, H. (2004) Maxillary sinus disease of odontogenic origin. Otolaryngologic Clinics of North America, 37, 347-364. doi:10.1016/S0030-6665(03)00171-3

[43] Brook, I. (2006) Sinusitis of odontogenic origin. Otolaryngology-Head and Neck Surgery, 135, 349-355. doi:10.1016/j.otohns.2005.10.059

[44] Osguthorpe, J.D. and Hadley, J.A. (1999) Rhinosinusitis. Current concepts in evaluation and management. Medical Clinics of North America, 83, 27-41. doi:10.1016/S0025-7125(05)70085-7

[45] Falk, H., Ericson, S. and Hugoson, A. (1986) The effects of periodontal treatment on mucous membrane thickening in the maxillary sinus. Journal of Clinical Periodontology, 13, 217-222. doi:10.1111/j.1600-051X.1986.tb01463.x

[46] Kretzschmar, D.P. and Kretzschmar, J.L. (2003) Rhinosinusitis: Review from a dental perspective. Oral Surgery, Oral Medicine, Oral Pathology, Oral Radiology and Endodontology, 96, 128-135. doi:10.1016/S1079-2104(03)00306-8

[47] Murphy, E. and Merrill, R.L. (2001) Non-odontogenic toothache. Journal of the Irish Dental Association, 47, 46-58.

[48] Rafetto, L. (1999) Clinical examination of the maxillary sinus. Oral and Maxillofacial Surgery Clinics of North America, 11, 35-44.

[49] Lipton, R.B., Bigal, M.E., Diamond, M., Freitag, F., Reed, M.L. and Stewart, W.F. (2007) Migraine prevalence, disease burden, and the need for preventive therapy. Neurology, 68, 343-349.

doi:10.1212/01.wnl.0000252808.97649.21

[50] Olesen, J. (2004) The international classification of headache disorders. Cephalalgia, 24, 9-160. doi:10.1111/j.1468-2982.2003.00824.x

[51] Lovshin, L.L. (1977) Carotidynia. Headache, 17, 192195. doi:10.1111/j.1526-4610.1977.hed1705192.x

[52] Alonso, A.A. and Nixdorf, D.R. (2006) Case series of four different headache types presenting as tooth pain. Journal of Endodontics, 32, 1110-1113. doi:10.1016/j.joen.2006.02.033

[53] Namazi, M.R. (2001) Presentation of migraine as odontalgia. Headache, 41, 420-421. doi:10.1046/j.1526-4610.2001.111006420.x

[54] Obermann, M., Mueller, D., Yoon, M.S., Pageler, L., Diener, H. and Katsarava, Z. (2007) Migraine with isolated facial pain: A diagnostic challenge. Cephalalgia, 27,
1278-1282. doi:10.1111/j.1468-2982.2007.01413.x

[55] Penarrocha, M., Bandres, A. and Bagan, J.V. (2004) Lower-half facial migraine: A report of 11 cases. Journal of Oral and Maxillofacial Surgery, 62, 1453-1456. doi:10.1016/j.joms.2004.01.027

[56] Benoliel, R. and Sharav, Y. (2008) Neurovascular orofacial pain. Cephalalgia, 28, 199-200.

[57] Goadsby, P.J. and Lipton, R.B. (1997) A review of paroxysmal hemicranias, SUNCT syndrome and other short-lasting headaches with autonomic feature, including new cases. Brain, 120, 193-209. doi:10.1093/brain/120.1.193

[58] Brooke, R.I. (1978) Periodic migrainous neuralgia: A cause of dental pain. Oral Surgery, Oral Medicine, Oral Pathology, 46, 511-516. doi:10.1016/0030-4220(78)90381-X

[59] Gross, S.G. (2006) Dental presentations of cluster headaches. Current Pain and Headache Reports, 10, 126-129. doi:10.1007/s11916-006-0023-1

[60] Bahra, A. and Goadsby, P.J. (2004) Diagnostic delays and mis-management in cluster headache. Acta Neurologica Scandinavica, 109, 175-179. doi:10.1046/i.1600-0404.2003.00237.x

[61] Bittar, G. and Graff-Radford, S.B. (1992) A retrospective study of patients with cluster headaches. Oral Surgery, Oral Medicine, Oral Pathology, 73, 519-525. doi:10.1016/0030-4220(92)90088-8

[62] Penarrocha, M., Bandres, A., Penarrocha, M.A. and Bagan, J.V. (2001) Relationship between oral surgical and endodontic procedures and episodic cluster headache. Oral Surgery, Oral Medicine, Oral Pathology Oral Radiol Endod, 92, 499-502. doi:10.1067/moe.2001.116153

[63] Sarlani, E., Schwartz, A.H., Greenspan, J.D. and Grace, E.G. (2003) Chronic paroxysmal hemicrania: A case report and review of the literature. Journal of Orofacial Pain, 17, 74-78.

[64] Antonaci, F. and Sjaastad, O. (1989) Chronic paroxysmal hemicrania $(\mathrm{CPH})$ : A review of the clinical manifestations. Headache, 29, 648-656. doi:10.1111/j.1526-4610.1989.hed2910648.x

[65] Benoliel, R. and Sharav, Y. (1998) Paroxysmal hemicrania. Case studies and review of the literature. Oral Surgery, Oral Medicine, Oral Pathology, Oral Radiology and Endodontology, 85, 285-292. doi:10.1016/S1079-2104(98)90010-5

[66] Benoliel, R., Elishoov, H. and Sharav, Y. (1997) Orofacial pain with vascular-type features. Oral Surgery, Oral Medicine, Oral Pathology, Oral Radiology and Endodontology, 84, 506-512. doi:10.1016/S1079-2104(97)90267-5

[67] Delcanho, R.E. and Graff-Radford, S.B. (1993) Chronic paroxysmal hemicrania presenting as toothache. Journal of Orofacial Pain, 7, 300-306.

[68] Moncada, E. and Graff-Radford, S.B. (1995) Benign indomethacin-responsive headaches presenting in the orofacial region: Eight case reports. Journal of Orofacial Pain, 9, 276-284.

[69] Benoliel, R. and Sharav, Y. (1998) SUNCT syndrome: Case report and literature review. Oral Surgery, Oral Medicine, Oral Pathology, Oral Radiology and Endodontology, 85, 158-161. doi:10.1016/S1079-2104(98)90419-X 
[70] Leone, M., Mea, E., Genco, S. and Bussone, G. (2006) Coexistence of TACS and trigeminal neuralgia: Pathophysiological conjectures. Headache, 46, 1565-1570. doi:10.1111/j.1526-4610.2006.00537.x

[71] de Siqueira, S.R., Nobrega, J.C., Teixeira, M.J. and de Siqueira, J.T. (2006) SUNCT syndrome associated with temporomandibular disorders: A case report. Cranio, 24, 300-302.

[72] Loeser, J.D. (2001) Bonica's management of pain. Lippincott Williams \&Wilkins, Philadelphia.

[73] Merrill, R.L. and Graff-Radford, S.B. (1992) Trigeminal neuralgia: How to rule out the wrong treatment. The Journal of the American Dental Association, 123, 63-68.

[74] Goddard, G. (1992) Case report of trigeminal neuralgia presenting as odontalgia. Cranio, 10, 245-247.

[75] Law, A.S. and Lilly, J.P. (1995) Trigeminal neuralgia mimicking odontogenic pain. A report of two cases. Oral Surgery, Oral Medicine, Oral Pathology, Oral Radiology and Endodontology, 80, 96-100. doi:10.1016/S1079-2104(95)80024-7

[76] Donlon, W.C. (1989) Odontalgia mimicking trigeminal neuralgia. Anesthesia Progress, 36, 98-100.

[77] Graff-Radford, S.B. and Solberg, W.K. (1993) Is atypical odontalgia a psychological problem? Oral Surgery, Oral Medicine, Oral Pathology, 75, 579-582. doi:10.1016/0030-4220(93)90228-V

[78] Clark, G.T. (2006) Persistent orodental pain, atypical odontalgia, and phantom tooth pain: When are they neuropathic disorders? Journal of the California Dental Association, 34, 599-609.

[79] Marbach, J.J. (1978) Phantom tooth pain. Journal of Endodontics, 4, 362-372. doi:10.1016/S0099-2399(78)80211-8

[80] Marbach, J.J. (1993) Phantom tooth pain: Differential diagnosis and treatment. The New York State Dental Journal, 59, 28-33.

[81] Kwan, C.L., Hu, J.W. and Sessle, B.J. (1993) Effects of tooth pulp deafferentation on brainstem neurons of the rat trigeminal subnucleus oralis. Somatosensory and Motor Research, 10, 115-131. doi:10.3109/08990229309028828

[82] Vickers, E.R., Cousins, M.J., Walker, S. and Chisholm, K. (1998) Analysis of 50 patients with atypical odontalgia. A preliminary report on pharmacological procedures for diagnosis and treatment. Oral Surgery, Oral Medicine, Oral Pathology, Oral Radiology and Endodontology, 85, 24-32. doi:10.1016/S1079-2104(98)90393-6

[83] Marbach, J.J. (1996) Orofacial phantom pain: Theory and phenomenology. The Journal of the American Dental Association, 127, 221-229.

[84] Solberg, W.K. and Graff-Radford, S.B. (1988) Orodental considerations in facial pain. Seminars in Neurology, 8, 318-323. doi:10.1055/s-2008-1041396

[85] Graff-Radford, S.B. and Solberg, W.K. (1992) Atypical odontalgia. Journal of Craniomandibular Disorders, 6, 260-265.

[86] Lilly, J.P. and Law, A.S. (1997) Atypical odontalgia misdiagnosed as odontogenic pain: A case report and discussion of treatment. Journal of Endodontics, 23, 337-339. doi:10.1016/S0099-2399(97)80419-0

[87] Truelove, E. (2004) Management issues of neuropathic trigeminal pain from a dental perspective. Journal of Orofacial Pain, 18, 374-380.
[88] Battrum, D.E. and Gutmann, J.L. (1996) Phantom tooth pain: A diagnosis of exclusion. International Endodontic Journal, 29, 190-194. doi:10.1111/j.1365-2591.1996.tb01368.x

[89] Reik, L. et al. (1985) Atypical facial pain: A reappraisal. Headache, 25, 30-32. doi:10.1111/j.1526-4610.1985.hed2501030.x

[90] Kreisberg, M.K. (1982) Atypical odontalgia: Differential diagnosis and treatment. The Journal of the American Dental Association, 104, 852-854.

[91] Klausner, J.J. (1994) Epidemiology of chronic facial pain: Diagnostic usefulness in patient care. The Journal of the American Dental Association, 125, 1604-1611.

[92] Ram, S., Teruel, A., Kumar, S.K. and Clark, G. (2009) Clinical characteristics and diagnosis of atypical odontalgia: Implications for dentists. The Journal of the American Dental Association, 140, 223-228.

[93] Pertes, R.A. and Heir, G.M. (1991) Chronic orofacial pain. A practical approach to differential diagnosis. Dental Clinics of North America, 35, 123-140.

[94] Rees, R.T. and Harris, M. (1979) Atypical odontalgia. British Journal of Oral Surgery, 16, 212-218. doi:10.1016/0007-117X(79)90027-1

[95] Cuffari, L., Tesseroli de Siqueira, J.T., Nemr, K. and Rapaport, A. (2006) Pain complaint as the first symptom of oral cancer: A descriptive study. Oral Surgery, Oral Medicine, Oral Pathology, Oral Radiology and Endodontology, 102, 56-61. doi:10.1016/j.tripleo.2005.10.041

[96] Gorsky, M., Epstein, J.B., Oakley, C., Le, N.D., Hay, J. and Stevenson-Moore, P. (2004) Carcinoma of the tongue: A case series analysis of clinical presentation, risk factors, staging, and outcome. Oral Surgery, Oral Medicine, Oral Pathology, Oral Radiology and Endodontology, 98, 546552. doi:10.1016/j.tripleo.2003.12.041

[97] Chaisuparat, R., Coletti, D., Kolokythas, A., Ord, R.A. and Nikitakis, N.G. (2006) Primary intraosseous odontogenic carcinoma arising in an odontogenic cyst or de novo: A clinicopathologic study of six new cases. Oral Surgery, Oral Medicine, Oral Pathology, Oral Radiology and Endodontology, 101, 194-200. doi:10.1016/j.tripleo.2005.03.037

[98] Epstein, J.B. and Jones, C.K. (1993) Presenting signs and symptoms of nasopharyngeal carcinoma. Oral Surgery, Oral Medicine, Oral Pathology, 75, 32-36. doi:10.1016/0030-4220(93)90402-P

[99] Reiter, S., Gavish, A., Winocur, E., Emodi-Perlman, A. and Eli, I. (2006) Nasopharyngeal carcinoma mimicking a temporomandibular disorder: A case report. Journal of Orofacial Pain, 20, 74-81.

[100] Cohen, S.G. and Quinn, P.D. (1988) Facial trismus and myofascial pain associated with infections and malignant disease. Report of five cases. Oral Surgery, Oral Medicine, Oral Pathology, 65, 538-544. doi:10.1016/0030-4220(88)90136-3

[101] Hauser, M.S. and Boraski, J. (1986) Oropharyngeal carcinoma presenting as an odontogenic infection with trismus. Oral Surgery, Oral Medicine, Oral Pathology, 61, 330-332. doi:10.1016/0030-4220(86)90411-1

[102] Barrett, A.P. (1984) Gingival lesions in leukemia. A classification. Journal of Periodontology, 55, 585-588.

[103] Epstein, J.B., Voss, N.J. and Stevenson-Moore, P. (1984) Maxillofacial manifestations of multiple myeloma. An 
unusual case and review of the literature. Oral Surgery, Oral Medicine, Oral Pathology, 57, 267-271. doi:10.1016/0030-4220(84)90182-8

[104] Abraham, P.J., Capobianco, D.J. and Cheshire, W.P. (2003) Facial pain as the presenting symptom of lung carcinoma with normal chest radiograph. Headache, 43, 499-504. doi:10.1046/j.1526-4610.2003.03097.x

[105] Capobianco, D.J. (1995) Facial pain as a symptom of nonmetastatic lung cancer. Headache, 35, 581-585. doi:10.1111/j.1526-4610.1995.hed3510581.x

[106] Eross, E.J., Dodick, D.W., Swanson, J.W. and Capobianco, D.J. (2003) A review of intractable facial pain secondary to underlying lung neoplasms. Cephalalgia, 23, 2-5. doi:10.1046/j.1468-2982.2003.00478.x

[107] Sarlani, E., Schwartz, A.H., Greenspan, J.D. and Grace, E.G. (2003) Facial pain as first manifestation of lung cancer: A case of lung cancer-related cluster headache and a review of the literature. Journal of Orofacial Pain, 17, 262-267.

[108] Hirshberg, A. and Buchner, A. (1995) Metastatic tumours to the oral region. An overview. European Journal of Cancer Part B Oral Oncology, 31, 355-360. doi:10.1016/0964-1955(95)00031-3

[109] D’Silva, N.J., Summerlin, D.J., Cordell, K.G., Abdelsayed, R.A., Tomich, C.E., Hanks, C.T., et al. (2006) Metastatic tumors in the jaws: A retrospective study of 114 cases. The Journal of the American Dental Association, 137, 1667-1672.

[110] Hirshberg, A., Leibovich, P. and Buchner, A. (1993) Metastases to the oral mucosa: Analysis of 157 cases. Journal of Oral Pathology and Medicine, 22, 385-390. doi:10.1111/j.1600-0714.1993.tb00128.x

[111] Hirshberg, A., Leibovich, P. and Buchner, A. (1994) Metastatic tumors to the jawbones: Analysis of 390 cases. Journal of Oral Pathology and Medicine, 23, 337-341. doi:10.1111/j.1600-0714.1994.tb00072.x

[112] American Psychiatric Association (1980) Diagnostic and Statistical Manual (DSM-III). 3rd Edition, Washington DC.

[113] Dworkin, S.F. and Burgess, J.A. (1987) Orofacial pain of psychogenic origin: Current concepts and classification. The Journal of the American Dental Association, 115, 565-571. 